\title{
Triptolide induces the cell apoptosis of osteosarcoma cells through the TRAIL pathway
}

\author{
XINGWEI ZHAO*, QIANG ZHANG* and LIANG CHEN \\ Department of Orthopaedics, Liaocheng People's Hospital and Liaocheng Clinical School \\ of Taishan Medical University, Liaocheng, Shandong, P.R. China
}

Received December 5, 2015; Accepted January 8, 2016

DOI: $10.3892 / o r .2016 .4957$

\begin{abstract}
Research on triptolide, a diterpenoid epoxide found in the Thunder God Vine Tripterygium wilfordii, has increased our knowledge of the pharmacology, pharmacokinetics, toxicology and clinical application of this agent. In the present study, we aimed to identify the effects of triptolide on the apoptosis of osteosarcoma cells and to evaluate the anti-proliferative action of this agent. MG-63 cells were treated either with various doses of triptolide $(50,100$ or $200 \mathrm{nM}$ ) or DMSO for 6, 12 and $24 \mathrm{~h}$. Treatment with triptolide effectively suppressed the cell viability and induced the apoptosis of osteosarcoma MG-63 cells as detected by MTT assay and flow cytometry, respectively. In addition, by using caspase- 3 , caspase- 8 and caspase- 9 activity assays and western blot analysis, the anticancer effects of triptolide against osteosarcoma growth were found to involve activation of the DR-5/p53/Bax/caspase-9/ caspase-3 signaling pathway and the DR-5/FADD/caspase-8/lysosomal/cathepsin B/caspase-3 signaling pathway in the MG-63 cells. An important factor in the anticancer effects of triptolide against osteosarcoma was TRAIL-DR-5. The data suggest that triptolide may be a potential novel chemotherapeutic agent for osteosarcoma and acts through the TRAIL-DR-5 signaling pathway.
\end{abstract}

\section{Introduction}

Osteosarcoma is a malignant bone cancer suffered by adolescents or children under the age of 20 years (1). It is a commonly observed pediatric malignant bone tumor and accounts for approximately $5 \%$ of all pediatric tumors (2). Osteosarcoma originates from mesenchymal tissues. Due to its high grade of malignancy and invasive ability, osteosarcoma presents with

Correspondence to: Dr Liang Chen, Department of Orthopaedics, Liaocheng People's Hospital and Liaocheng Clinical School of Taishan Medical University, 67 Dongchang West Road, Dongchangfu, Liaocheng, Shandong, P.R. China

E-mail: chengpu64737@126.com

${ }^{*}$ Contributed equally

Key words: triptolide, osteosarcoma, TRAIL, DR-5 lung metastasis at an early stage. Therefore, its prognosis is poor and survival rates are low. The 5-year survival rate after amputation is only $5-15 \%$ (3). More and more studies have confirmed that oncotherapy for malignant cancer, particularly solid tumors includes comprehensive therapy consisting of chemotherapy, radiotherapy and molecular-targeted treatment (4). The introduction and development of molecular-targeted treatment brings good news to osteosarcoma patients $(5,6)$.

Apoptosis is a self-destruction mechanism in cells. In this process, organisms can scavenge aging and abnormal cells (7). The major strategy of molecular-targeted treatment is to induce cancer cells to deform and initiate programmed cell death to scavenge tumor cells (8).

The occurrence and progression of osteosarcoma are not only the result of uncontrolled cell proliferation and abnormal differentiation, but are also related with the unbalance of cell apoptosis (9). During the initiation process, apoptosis is inhibited, cell cycle regulation is destroyed and neoplasm occurs.

Tumor necrosis factor-related apoptosis-inducing ligand (TRAIL) is an important activating agent for cell apoptosis (10). It can selectively induce osteosarcoma cells to apoptosis by combining with its ligands while it is not sensitive to normal cells. This is because its regulation to induce apoptosis is realized by distribution levels of receptors. TRAIL receptors include death receptors and decoy receptors (9). Death receptors are widely distributed on cell surfaces, including cancer cells and normal cells. Decoy receptors are not expressed in most tumor cell surfaces, but are selectively expressed on normal cell surfaces (11). Differences in the expression levels of surface receptors in tumor cells and normal cells is an essential cause of the various lethality of TRAIL. Only by this regulation of expression levels, TRAIL confers its specific antitumor functions (12).

TRAIL (TNF-related apoptosis-inducing ligand) is a newly found family member of the tumor necrosis factor (13). It can selectively induce various tumor cells to apoptosis while it does not affect the growth and differentiation of normal cells. It can rapidly induce apoptosis of specific receptors (14). In addition, cysteine aspastic acid-specific protease 3 (caspase-3) and caspase- 8 are important initiation factors of the caspase family and play a fundamental role in cell apoptosis (15).

Triptolide, a diterpenoid epoxide found in the Thunder God Vine Tripterygium wilfordii has various pharmacological actions such as anti-inflammation, immunosuppression, antitumor and anti-fertility and is widely 
employed in autoimmunity and inflammatory diseases such as rheumatic arthritis, rheumatoid arthritis, nephritis, asthma, systemic lupus erythematosus and dermatosis $(16,17)$. Its active ingredients consist of epoxyditerpenes, triterpenes and alkaloid. As a diterpene monomer, triptolide is the main active ingredient extracted from Thunder God Vine $(16,18)$. In addition, the present study explores the possible mechanisms of triptolide on osteosarcoma, in order to set the basis for novel strategies in other cancer.

\section{Materials and methods}

Cell culture and reagents. The MG-63 human osteosarcoma cell line was obtained from Shanghai Cell Bank (Shanghai, China) and was maintained in Dulbecco's modified Eagle's medium (DMEM) with $10 \%$ fetal bovine serum (FBS) (both from Invitrogen, Carlsbad, CA, USA) and $2 \mathrm{mM} \mathrm{L}$-glutamine at $37^{\circ} \mathrm{C}$ with $5 \% \mathrm{CO}_{2}$.

MTT assay. MG-63 cells ( $1 \times 10^{4}$ cell/well) grown in 96-well culture plates were treated either with various doses of triptolide (50, 100 or $200 \mathrm{nM}$ ) or DMSO for 6, 12 and $24 \mathrm{~h}$. MTT was added at a final concentration of $0.5 \mathrm{mg} / \mathrm{ml}$ and incubated at $37^{\circ} \mathrm{C}$ for $4 \mathrm{~h}$. DMSO (Invitrogen) was added to each well to dissolve the formazan crystals. Cell viability was measured using a microplate reader (Model 550; Bio-Rad, Hercules, CA, USA) at $570 \mathrm{~nm}$ wavelength.

Cell apoptosis assays. MG-63 cells ( $1 \times 10^{6}$ cell/well) grown in 6-well culture plates were treated either with various doses of triptolide $(50,100$ or $200 \mathrm{nM}$ ) or DMSO for $12 \mathrm{~h}$. MG-63 cells were washed once with ice-cold PBS and incubated using the Annexin V-fluorescein isothiocyanate (FITC) kit (Sigma-Aldrich). Cell apoptosis was detected using flow cytometry according to the manufacturer's instructions.

Detection of caspase-3, caspase- 8 and caspase- 9 activity. MG-63 cells $\left(1 \times 10^{4}\right.$ cell/well) grown in 96-well culture plates were treated either with various doses of triptolide $(50,100$ or $200 \mathrm{nM}$ ) or DMSO for $12 \mathrm{~h}$. Caspase-Glo reagent (100 $\mu \mathrm{l})$ (Ac-DEVD-pNA for caspase-3, Ac-IETD-pNA for caspase-8, Ac-LEHD-pNA for caspase-9) was added to each well in culture medium for $45 \mathrm{~min}$ at room temperature. Caspase-3, caspase- 8 and caspase- 9 activity was measured using a microplate reader (Model 550; Bio-Rad) at $405 \mathrm{~nm}$ wavelength.

Western blot analysis. MG-63 cells ( $1 \times 10^{6}$ cell/well) grown in 6-well culture plates were treated either with various doses of triptolide (50, 100 or $200 \mathrm{nM}$ ) or DMSO for $12 \mathrm{~h}$. MG-63 cells were lysed in ice-cold lysing buffer consisting of $50 \mathrm{mM}$ Trizma base ( $\mathrm{pH}$ 7.4; Sigma-Aldrich) and centrifuged at $13,000 \mathrm{x} \mathrm{g}$ for $10 \mathrm{~min}$ at $4^{\circ} \mathrm{C}$. The protein expression levels were measured using the BCA assay (Beyotime Biotechnology, Jiangsu, China). Proteins (50 $\mu \mathrm{g} /$ lane) were separated on 12\% SDS-PAGE gels and then transferred to polyvinylidene difluoride membranes (Bio-Rad). After electro-transfer, the membranes were blocked with 5\% nonfat milk in TBST buffer. Next, the membranes were probed with primary mouse monoclonal anti-human antibodies for death receptor 5 (DR-5), p53, BAX, pro-caspase- 8 , c-FLIP, lysosomal, cathepsin B

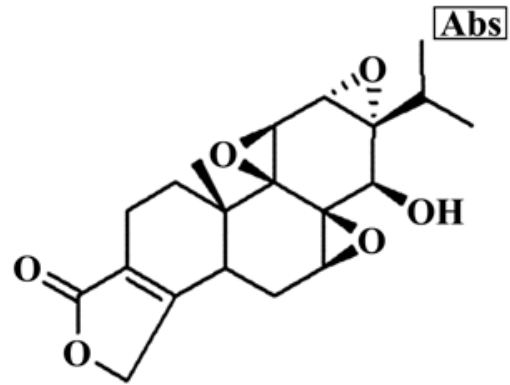

Figure 1. Chemical structure of triptolide.

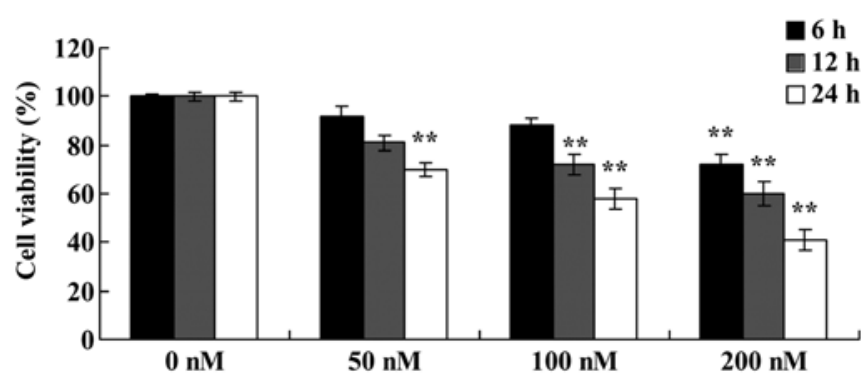

Figure 2. Triptolide suppressed the viability of osteosarcoma MG-63 cells. ${ }^{* *} \mathrm{P}<0.01$ compared with the MG- 63 cells treated with $0 \mathrm{nM}$ of triptolide.

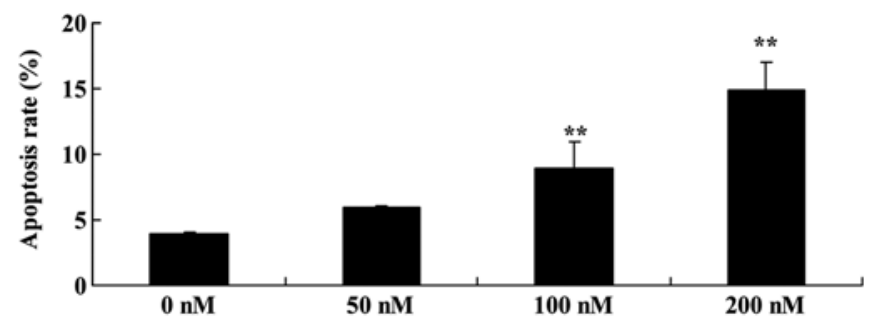

Figure 3. Triptolide induced the apoptosis of osteosarcoma MG-63 cells. ${ }^{* *} \mathrm{P}<0.01$ compared with the MG- 63 cells treated with $0 \mathrm{nM}$ of triptolide.

and $\beta$-actin diluted in blocking buffer to a concentration of 1:2,000 at $4^{\circ} \mathrm{C}$ overnight. Blots were incubated with horseradish (HRP)-conjugated secondary antibodies, detected with enhanced chemiluminescence reagent (Sangon Biotech Co., Ltd., Shanghai, China). The protein expression was analyzed using TotalLab software (Nonlinear Dynamics).

Statistical analysis. The results are expressed as the mean \pm SD. Qualitative data were analyzed using the $\chi^{2}$ test. $\mathrm{P}<0.05$ was considered to indicate a statistically significant difference.

\section{Results}

Triptolide suppresses the viability of osteosarcoma cells. The chemical structure of triptolide is showed in Fig. 1. MG-63 cells were treated with increasing doses of triptolide $(50,100$ or $200 \mathrm{nM}$ ) for $24 \mathrm{~h}$. As shown in Fig. 2, triptolide inhibited the viability of the MG-63 cells in a dose- and time-dependent manner. The cell viability was significantly reduced at $50 \mathrm{nM}$ for $24 \mathrm{~h} ; 100 \mathrm{nM}$ for 12 or $24 \mathrm{~h}$; and $100 \mathrm{nM}$ for 6,12 or 
A

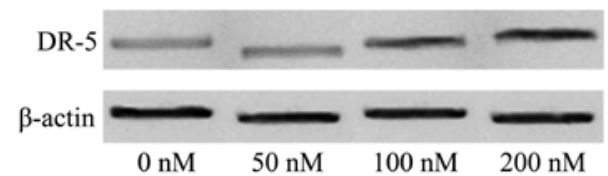

B

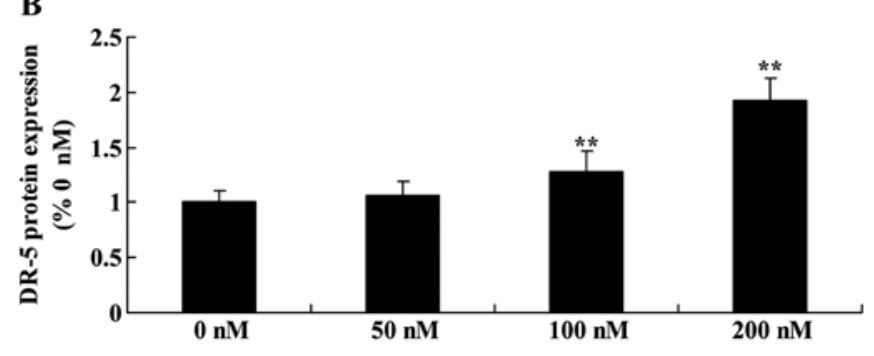

Figure 4. Triptolide increases DR-5 protein in the osteosarcoma cells. Triptolide increased DR-5 protein expression in the osteosarcoma cells as shown by (A) western blotting and (B) quantification of the results. ${ }^{* *} \mathrm{P}<0.01$ compared with the MG-63 cells treated with $0 \mathrm{nM}$ of triptolide.

A

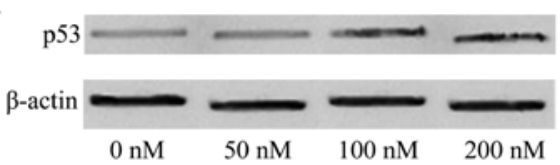

B

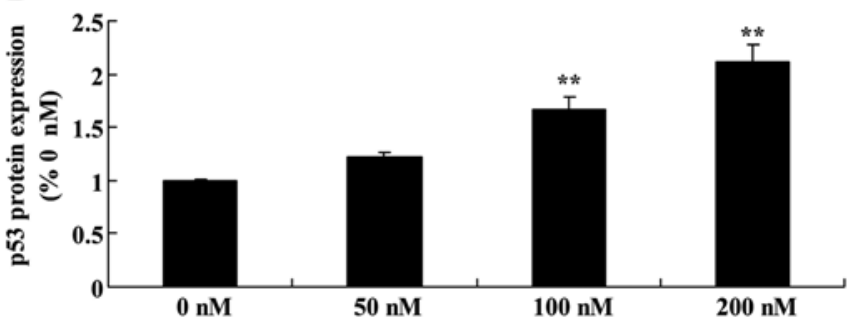

Figure 5. Triptolide increases p53 protein in the osteosarcoma cells. Triptolide increased $\mathrm{p} 53$ protein expression in the osteosarcoma cells as shown by (A) western blotting and (B) quantification of the results. ${ }^{* *} \mathrm{P}<0.01$ compared with the MG-63 cells treated with $0 \mathrm{nM}$ of triptolide.

$24 \mathrm{~h}$ (Fig. 2). These results indicate that triptolide suppressed the viability of the MG-63 cells, which may contribute to a cure for osteosarcoma.

Triptolide induces the cell apoptosis of osteosarcoma. The effect of triptolide on the apoptosis of osteosarcoma cells was investigated. We found that the cell apoptosis of MG-63 cells was significantly induced in a dose-dependent manner following treatment with 100 or $200 \mathrm{nM}$ of triptolide for 12 h (Fig. 3).

Triptolide increases DR-5 protein in osteosarcoma cells. The role of triptolide in the DR-5 signaling pathway was examined. DR-5 protein expression was detected using western blotting in the MG-63 cells treated with 50, 100 or $200 \mathrm{nM}$ triptolide. As shown in Fig. 4, treatment with 100 or $200 \mathrm{nM}$ of triptolide for $12 \mathrm{~h}$ significantly increased DR-5 protein expression in
$\mathbf{A}$

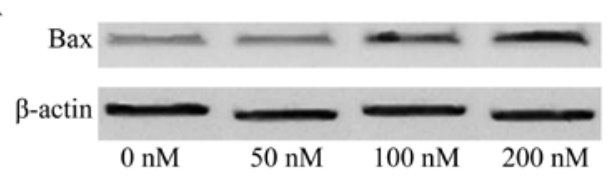

B

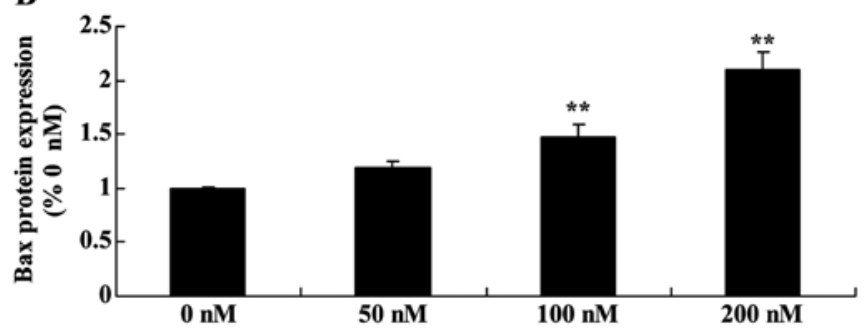

Figure 6. Triptolide increases Bax protein in the osteosarcoma cells Triptolide increased Bax protein expression in the osteosarcoma cells as shown by (A) western blotting and (B) quantification of the results. ${ }^{* *} \mathrm{P}<0.01$ compared with the MG-63 cells treated with $0 \mathrm{nM}$ of triptolide.

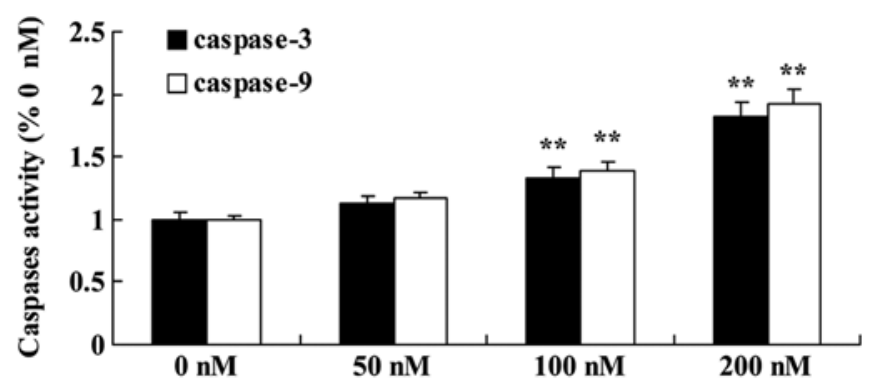

Figure 7. Triptolide increased caspase-9/-3 activity in the osteosarcoma cells. ${ }_{* *} \mathrm{P}<0.01$ compared with the MG-63 cells treated with $0 \mathrm{nM}$ of triptolide.

a dose-dependent manner, compared with the level in cells treated with DMSO.

Triptolide increases p53 protein in osteosarcoma cells. Given that MG-63 cells are resistant to triptolide treatment, we focused on the p53 protein in the following study. There was a significant increase in p53 protein expression in the MG-63 cells following treatment of triptolide at 100 or $200 \mathrm{nM}$, compared with the level in cells treated with DMSO (Fig. 5).

Ttriptolide increases Bax protein in osteosarcoma cells. To assess triptolide/TRAIL-induced MG-63 cell apoptosis, the Bax signaling pathway of apoptosis was analyzed. Triptolide (100 or $200 \mathrm{nM}$ ) significantly activated Bax protein expression in the MG-63 cells, compared with the level in cells treated with DMSO (Fig. 6).

Triptolide increases caspase-9/ caspase-3 activity in osteosarcoma cells. MG-63 cells were incubated with triptolide (50, 100 or $200 \mathrm{nM}$ ) for $12 \mathrm{~h}$. Incubation of the MG-63 cells in culture medium containing 100 or $200 \mathrm{nM}$ triptolide resulted in a statistically significant increase in caspase-9/-3 activity in a dose-dependent manner, compared with the activity noted in the cells treated with DMSO (Fig. 7). 
$\mathbf{A}$

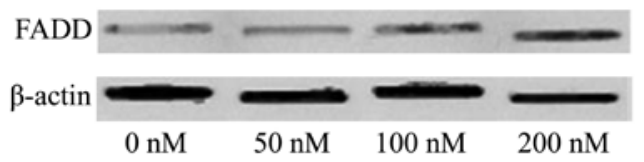

B

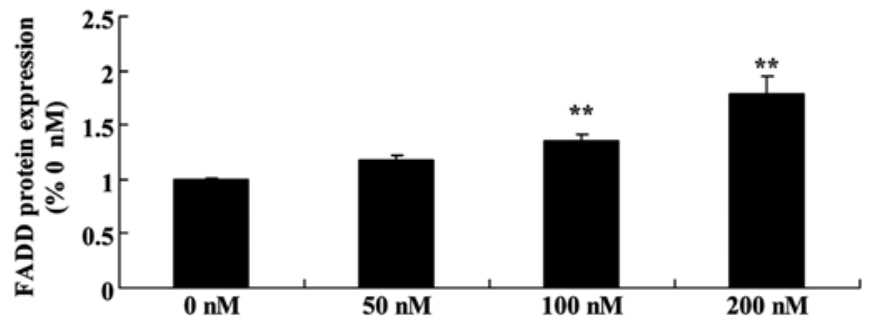

Figure 8. Triptolide increases FDAA protein in the osteosarcoma cells. Triptolide increased FDAA protein expression in the osteosarcoma cells as shown by (A) western blotting and (B) quantification of the results. ${ }^{* *} \mathrm{P}<0.01$ compared with the MG- 63 cells treated with $0 \mathrm{nM}$ of triptolide.

A

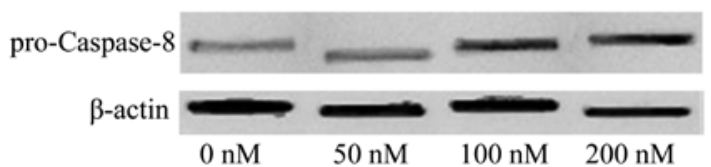

B

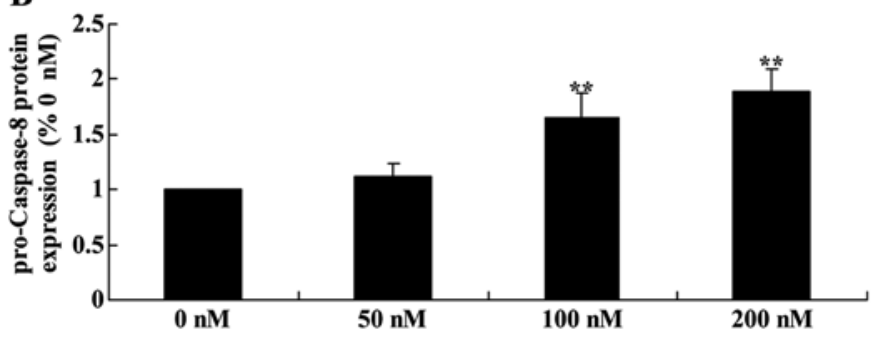

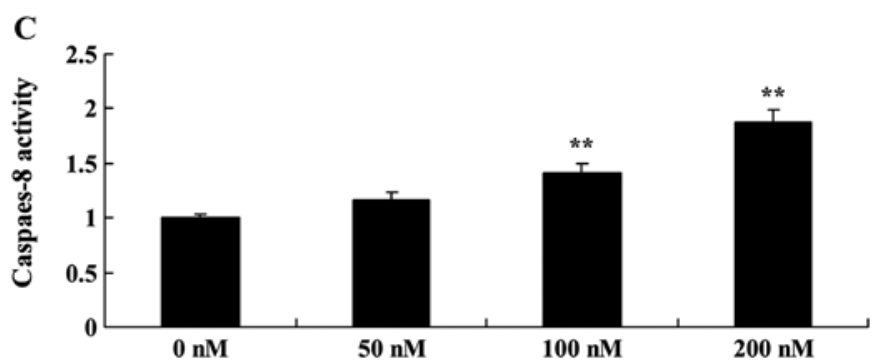

Figure 9. Triptolide increases pro-caspase- 8 protein and caspase- 8 activity in osteosarcoma cells. Triptolide increased pro-caspase- 8 protein expression as determined by (A) western blotting and (B) quantification of the results. (C) caspase- 8 activity in the osteosarcoma cells. ${ }^{* *} \mathrm{P}<0.01$ compared with the MG-63 cells treated with $0 \mathrm{nM}$ of triptolide.

A

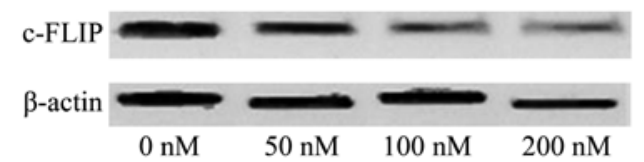

B

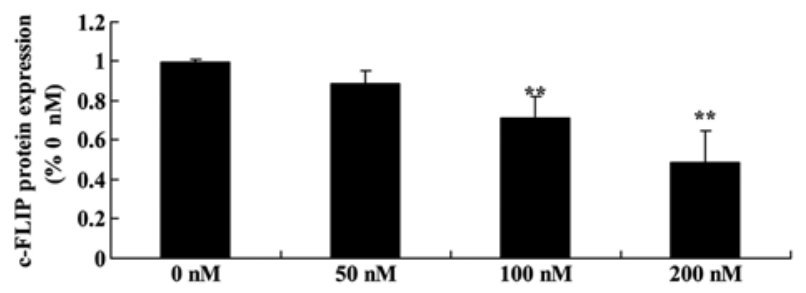

Figure 10. Triptolide suppresses c-FLIP protein in osteosarcoma cells. Triptolide suppressed c-FLIP protein expression in the osteosarcoma cells as shown by (A) western blotting and (B) quantification of the results. ${ }^{* *} \mathrm{P}<0.01$ compared with the MG-63 cells treated with $0 \mathrm{nM}$ of triptolide.

Triptolide increases FDAA protein in osteosarcoma cells. In general, TRAIL triggers apoptosis through binding to the FDAA apoptosis signaling pathway. Triptolide (100 or $200 \mathrm{nM}$ ) treatment markedly increased the expression of FDAA protein in a dose-dependent manner in the MG-63 cells (Fig. 8).

Triptolide increases pro-caspase- 8 protein and caspase- 8 activity in osteosarcoma cells. To explore the underlying mechanism that may be responsible for the anticancer effect of triptolide on apoptosis, we examined pro-caspase- 8 protein and caspase- 8 activity in the MG-63 cells. Treatement of triptolide at 100 and $200 \mathrm{nM}$ significantly increased pro-caspase- 8 protein expression and caspase- 8 activity in the MG-63 cells (Fig. 9).

Triptolide suppresses c-FLIP protein in osteosarcoma cells. To verify whether c-FLIP upregulation is responsible for the anticancer effect of triptolide on the apoptosis of osteosarcoma cells, we measured c-FLIP protein expression using western blot analysis. As shown in Fig. 10, c-FLIP protein expression was significantly suppressed in the MG-63 cells following treatment with triptolide (100 or $200 \mathrm{nM}$ ) (Fig. 10).

Ttriptolide increases LMP protein in osteosarcoma cells. We examined whether LMP activation is involved in the anticancer effects of triptolide on TRAIL-induced apoptosis 
$\mathbf{A}$

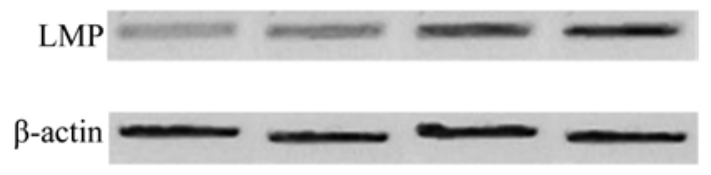

B

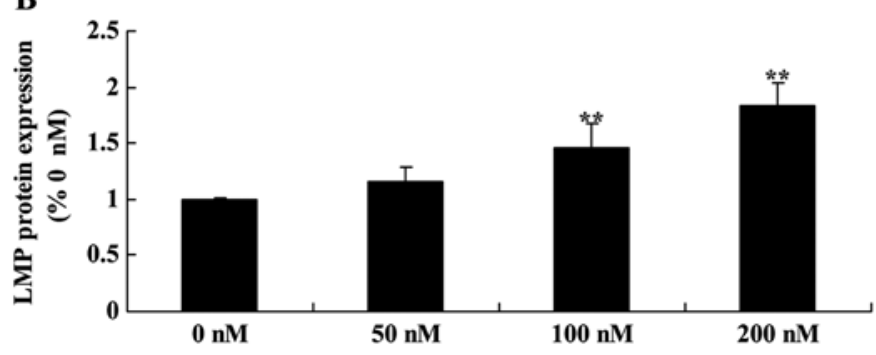

Figure 11. Triptolide increases LMP protein in osteosarcoma cells. Triptolide increased LMP protein expression in the osteosarcoma cells as shown by (A) western blotting and (B) quantification of the results. ${ }^{* *} \mathrm{P}<0.01$ compared with the MG- 63 cells treated with $0 \mathrm{nM}$ of triptolide.

A

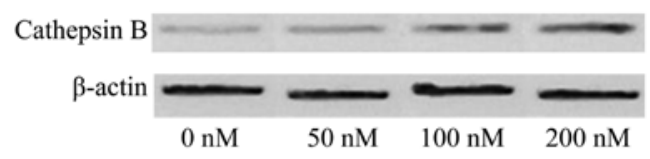

B

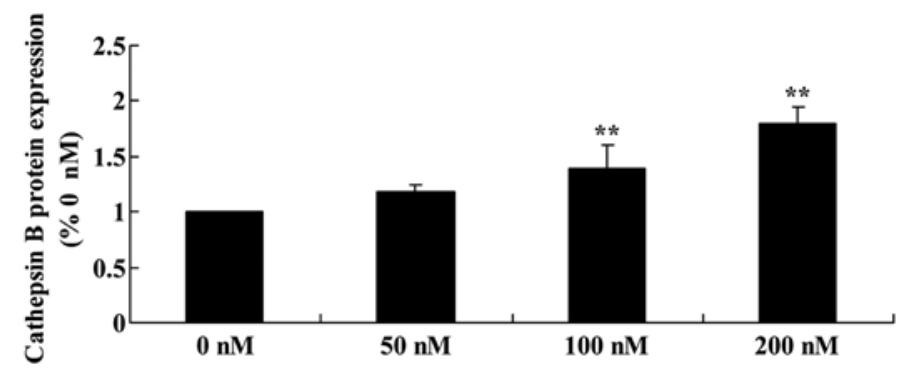

Figure 12. Triptolide increases cathepsin B protein in osteosarcoma cells. Triptolide increased the cathepsin B protein expression in the osteosarcoma cells as shown by (A) western blotting and (B) quantification of the results. ${ }^{* *} \mathrm{P}<0.01$ compared with the MG-63 cells treated with 0 nM of triptolide.

in MG-63 cells. The results revealed that 100 and $200 \mathrm{nM}$ of triptolide significantly promoted the LMP protein expression in MG-63 cells (Fig. 11).

Triptolide increases cathepsin B protein in osteosarcoma cells. We next examined whether activation of cathepsin $\mathrm{B}$ is involved in the anticancer effects of triptolide on osteosarcoma cells. Furthermore, the protein expression of cathepsin B was significantly enhanced following treatment with 100 and $200 \mathrm{nM}$ of triptolide, compared with the cells treated with DMSO (Fig. 12).

\section{Discussion}

Characterized by high malignant potential and invasive ability, osteosarcoma, a common tumor in adolescents, exhibits lung metastasis at an early stage (19). Consequently, it is associated with a poor prognosis and a low survival rate. The pathogenesis of osteosarcoma is still being researched. It is now realized that tumors are the result of uncontrolled cell growth and differentiation as protooncogenes are activated. It is polygenic and involves multiple factors (20). Tumorigenesis is closely related with multiple genes (21). More and more studies confirm that oncotherapy for malignant cancer, particularly solid tumors includes comprehensive therapy consisting of chemotherapy, radiotherapy and molecular-targeted treatment (6). The results obtained in the present study demonstrated that triptolide significantly suppressed the cell viability and induced the cell apoptosis of osteosarcoma. Reno et al reported that triptolide inhibited cell migration, invasion and metastasis of lung cancer cells (22). Therefore, we hypothesized that triptolide may reduce the growth of osteosarcoma cells.
Caspase- 8 is a cysteine proteinase, distributed in tissues and cell lines, such as bones and cartilages (23). With FADD-like death effector domain, it participates in cell apoptosis mechanisms and can combine with FADD through death effector domain (24). Caspase-8 participates in cell apoptosis through forming a death-inducing signaling complex (25). The caspase protease family occupies the central role in the apoptosis process and participates directly in early initiation, signal transmission and late apoptotic effects (26). Caspase- 8 is at the peak of the cascade reaction. Its expression not only reflects apoptosis levels but also reflects the existence of apoptosis initiators, suggesting that the occurrence of osteosarcoma is related with low expression of caspase-8 (27). However, the expression of caspase- 8 in malignant cancer is still controversial. Some scholars have found that upregulated expression of caspase- 8 indicates poor prognosis. This may be due to the fact that in highly proliferative tissues, apoptosis may be facilitated, which reflects the complexity of apoptosis and proliferation (28). During the pathological processes of osteosarcoma, inhibition of apoptosis due to the inactivation of cancer-suppressor genes is the main cause, therefore, caspase- 8 has low expression (29). These data together indicate that triptolide significantly increased pro-caspase- 8 protein expression and caspase- 8 activity in the MG- 63 cells. Zhao et al reported that triptolide induced growth inhibition and apoptosis through caspase-8/ caspase-9, and p53 expression in human laryngocarcinoma cells (30).

Studies suggest that DR-5 is expressed in normal cells, such as foetal livers and lungs as well as adult livers, lungs, lymphocytes, ovary and spleens (31). Particularly, it has higher expression in tumor tissues of lung cancer, breast carcinoma, ovarian cancer, rectal cancer and cervical cancer $(31,32)$. DR-5 


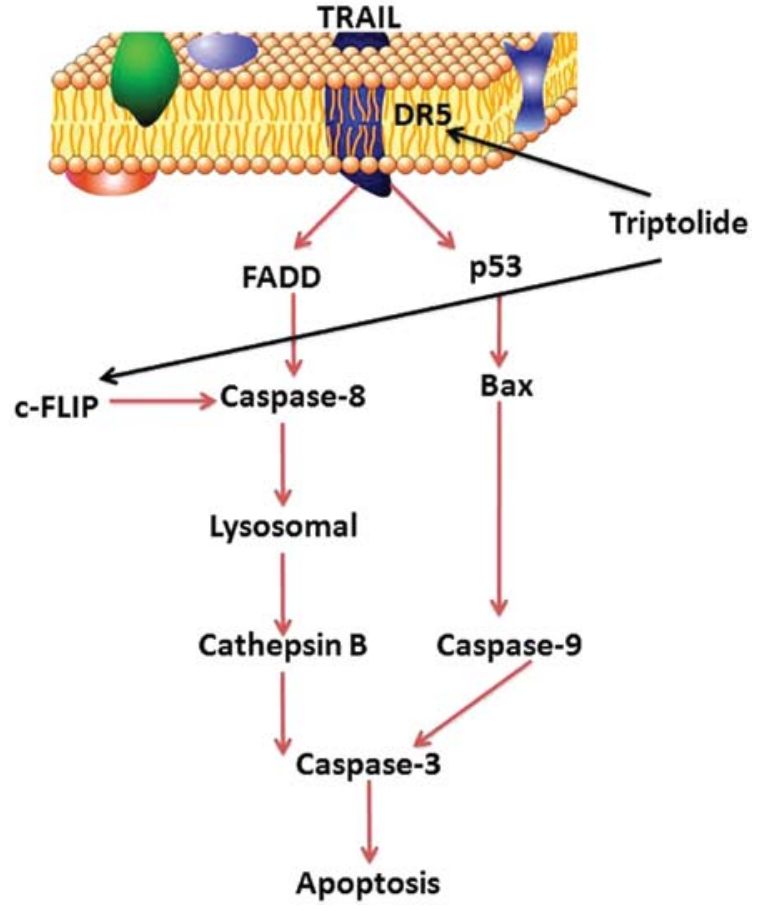

Figure 13. Anticancer effect of triptolide in osteosarcoma cells is by induction of cell apoptosis through the TRAIL pathway.

is an important target protein of the effects of anticancer drugs. Under normal conditions, DR-5 has higher activity, which is possibly related with its stability (11). Overexpression of DR-5 can directly induce cells to undergo exogenous apoptosis. In the present study, triptolide increased DR-5, p53 and Bax protein expression, and promoted caspase-9/-3 activity in the osteosarcoma cells. Carter et al reported that triptolide sensitized acute myeloid leukemia (AML) cells (33).

c-FLIP is an important anti-apoptotic protein in the exogenous apoptosis signaling pathway. Studies have confirmed that compared with normal cells, c-FLIP is upregulated in various types of tumors (34). High expression of c-FLIP is related with tumor metastasis and poor prognosis. It was reported that c-FLIP contains three alternative splice variantsc-FLIPt, c-FLIPs and c-FLIPr (35). c-FLIP contains two DED structural domains. c-FLIPs has about 20 amino acids and these amino acids are important for the ubiquitination and degradation of c-FLIPs (35). In comparison to c-FLIPs, c-FLIP has a lack of amino acid sequence at C. c-FLIP has a longer c-terminus and is similar with pro-caspase-8 in structure (29). Additionally, c-FLIP has a cleavage site of caspase- 8 and can be incised at the Asp-376 (LEVD) site. After incision, it can produce fragments with enzymatic activities: p43-c-FLlp. c-FLIPL-pro-caspase-8/caspase-10 heterodimer is probably more stable than pro-caspase-8/caspase-10 homodimer (36). The present results demonstrated that triptolide significantly suppressed c-FLIP protein expression in the MG-63 cells. Chen et al reported that triptolide sensitized pancreatic cancer cells through suppression of c-FLIP protein expression (37).

Studies have found that as an upstream molecule of the osteogenesis signal pathway, LMP-1 can accumulate many osteoblastic genes to participate in osteogenic differentiation and osteogenesis (38). Three types of spliceosomes of LMP are LMP-1, LMP-2 and LMP-3 (39). It was suggested that
LMP-1 could inhibit malignant phenotypes of osteosarcoma through facilitating osteogenic differentiation of osteosarcoma cells (40). The present results showed that triptolide increased LMP protein in the osteosarcoma cells. Owa et al reported that triptolide induced lysosomal-mediated programmed cell death in MCF-7 breast cancer cells through LMP (16).

Cathepsin B is related with the decomposition of laminin in the extracellular matrix (41). Laminin is the main ingredient of the basilar membrane which is associated with tumor invasion and metastasis. In addition, it can degrade fibronectin and collagen type IV (42). In the present study, triptolide increased cathepsin B protein in the osteosarcoma cells. Owa et al reported that triptolide induced lysosomal-mediated programmed cell death in MCF-7 breast cancer cells through cathepsin B and caspase-3 (16).

In conclusion, the present study indicated that triptolide significantly suppressed cell viability, induced cell apoptosis of osteosarcoma cells in vitro, and evidence was presented that its anticancer effects may be associated with the activation of the DR-5/p53/Bax/caspase-9/-3 signaling pathway and the DR-5/FADD/caspase-8/lysosomal/cathepsin B/caspase-3 signaling pathway in MG-63 cells (Fig. 13). However, further in-depth studies are required to investigate the possible molecular mechanisms of triptolide, and whether triptolide could be effectively applied in clinical practice.

\section{References}

1. Ferrari S, Meazza C, Palmerini E, Tamburini A, Fagioli F, Cozza R, Ferraresi V, Bisogno G, Mascarin M, Cefalo G, et al: Nonmetastatic osteosarcoma of the extremity. Neoadjuvant chemotherapy with methotrexate, cisplatin, doxorubicin and ifosfamide. An Italian Sarcoma Group study (ISG/OS-Oss). Tumori 100: 612-619, 2014.

2. Zalupski MM, Rankin C, Ryan JR, Lucas DR, Muler J, Lanier KS, Budd GT, Biermann JS, Meyers FJ and Antman K: Adjuvant therapy of osteosarcoma - A phase II trial: Southwest Oncology Group study 9139. Cancer 100: 818-825, 2004.

3. Nagarajan R, Clohisy DR, Neglia JP, Yasui Y, Mitby PA, Sklar C, Finklestein JZ, Greenberg M, Reaman GH, Zeltzer L, et al: Function and quality-of-life of survivors of pelvic and lower extremity osteosarcoma and Ewing's sarcoma: The Childhood Cancer Survivor Study. Br J Cancer 91: 1858-1865, 2004.

4. Berg J, Gebhardt MC and Rand WM: Effect of timing of postoperative chemotherapy on survival of dogs with osteosarcoma. Cancer 79: 1343-1350, 1997.

5. Grignani G, Palmerini E, Ferraresi V, D'Ambrosio L, Bertulli R, Asaftei SD, Tamburini A, Pignochino Y, Sangiolo D, Marchesi E, et al; Italian Sarcoma Group: Sorafenib and everolimus for patients with unresectable high-grade osteosarcoma progressing after standard treatment: A non-randomised phase 2 clinical trial. Lancet Oncol 16: 98-107, 2015.

6. Petrilli AS, de Camargo B, Filho VO, Bruniera P, Brunetto AL, Jesus-Garcia R, Camargo OP, Pena W, Péricles P, Davi A, et al; Brazilian Osteosarcoma Treatment Group Studies III and IV: Results of the Brazilian Osteosarcoma Treatment Group Studies III and IV: Prognostic factors and impact on survival. J Clin Oncol 24: 1161-1168, 2006.

7. Yan M, Ni J, Song D, Ding M and Huang J: Activation of unfolded protein response protects osteosarcoma cells from cisplatin-induced apoptosis through NF-kB pathway. Int J Clin Exp Pathol 8: 10204-10215, 2015.

8. Yang TM, Qi SN, Zhao N, Yang YJ, Yuan HQ, Zhang B and Jin S: Induction of apoptosis through caspase-independent or caspase-9-dependent pathway in mouse and human osteosarcoma cells by a new nitroxyl spin-labeled derivative of podophyllotoxin. Apoptosis 18: 727-738, 2013.

9. Hanikoglu F, Cort A, Ozben H, Hanikoglu A and Ozben T: Epoxomicin sensitizes resistant osteosarcoma cells to TRAIL induced apoptosis. Anticancer Agents Med Chem 15: 527-533, 2015. 
10. Hotta T, Suzuki H, Nagai S, Yamamoto K, Imakiire A, Takada E, Itoh $\mathrm{M}$ and Mizuguchi J: Chemotherapeutic agents sensitize sarcoma cell lines to tumor necrosis factor-related apoptosis-inducing ligand-induced caspase- 8 activation, apoptosis and loss of mitochondrial membrane potential. J Orthop Res 21: 949-957, 2003.

11. Locklin RM, Federici E, Espina B, Hulley PA, Russell RG and Edwards CM: Selective targeting of death receptor 5 circumvents resistance of MG-63 osteosarcoma cells to TRAIL-induced apoptosis. Mol Cancer Ther 6: 3219-3228, 2007.

12. Sonnemann J, Trommer N, Becker S, Wittig S, Grauel D, Palani CD and Beck JF: Histone deacetylase inhibitor-mediated sensitization to TRAIL-induced apoptosis in childhood malignancies is not associated with upregulation of TRAIL receptor expression, but with potentiated caspase- 8 activation. Cancer Biol Ther 13: 417-424, 2012.

13. Sage EK, Kolluri KK, McNulty K, Lourenco SS, Kalber TL, Ordidge KL, Davies D, Gary Lee YC, Giangreco A and Janes SM: Systemic but not topical TRAIL-expressing mesenchymal stem cells reduce tumour growth in malignant mesothelioma. Thorax 69: 638-647, 2014.

14. Lamothe B and Aggarwal BB: Ectopic expression of Bcl-2 and Bcl-xL inhibits apoptosis induced by TNF-related apoptosis-inducing ligand (TRAIL) through suppression of caspases-8 7 , and 3 and BID cleavage in human acute myelogenous leukemia cell line HL-60. J Interferon Cytokine Res 22: 269-279, 2002.

15. Saggioro FP, Neder L, Stávale JN, Paixão-Becker AN, Malheiros SM, Soares FA, Pittella JE, Matias CC, Colli BO, Carlotti CG Jr, et al: Fas, FasL, and cleaved caspases 8 and 3 in glioblastomas: A tissue microarray-based study. Pathol Res Pract 210: 267-273, 2014

16. Owa C, Messina ME Jr and Halaby R: Triptolide induces lysosomal-mediated programmed cell death in MCF-7 breast cancer cells. Int J Womens Health 5: 557-569, 2013.

17. Pan J: RNA polymerase - an important molecular target of triptolide in cancer cells. Cancer Lett 292: 149-152, 2010.

18. Liu Q: Triptolide and its expanding multiple pharmacological functions. Int Immunopharmacol 11: 377-383, 2011.

19. Alvarez FJ, Kisseberth W, Hosoya K, Lara-Garcia A, Kosarek C, Murahari S, Au JL, Wientjes MG, Couto J and Couto G: Postoperative adjuvant combination therapy with doxorubicin and noncytotoxic suramin in dogs with appendicular osteosarcoma. J Am Anim Hosp Assoc 50: 12-18, 2014

20. Arndt CA, Koshkina NV, Inwards CY, Hawkins DS, Krailo MD, Villaluna D, Anderson PM, Goorin AM, Blakely ML, Bernstein M, et al: Inhaled granulocyte-macrophage colony stimulating factor for first pulmonary recurrence of osteosarcoma: Effects on disease-free survival and immunomodulation. A report from the Children's Oncology Group. Clin Cancer Res 16: 4024-4030, 2010.

21. Rakha EA, Tan PH, Shaaban A, Tse GM, Esteller FC, van Deurzen CH, Purnell D, Stotter A, Chan T, Yamaguchi R, et al: Do primary mammary osteosarcoma and chondrosarcoma exist? A review of a large multi-institutional series of malignant matrix-producing breast tumours. Breast 22: 13-18, 2013.

22. Reno TA, Kim JY and Raz DJ: Triptolide inhibits lung cancer cell migration, invasion, and metastasis. Ann Thorac Surg 100 1817-1824, discussion 1824-1825, 2015.

23. van Raam BJ and Salvesen GS: Proliferative versus apoptotic functions of caspase- 8 Hetero or homo: The caspase- 8 dimer controls cell fate. Biochim Biophys Acta 1824: 113-122, 2012.

24. Saitoh Y,Hamano A, Mochida K, Kakeya A, Uno M, TsuruyamaE, Ichikawa $\mathrm{H}$, Tokunaga $\mathrm{F}$, Utsunomiya A, Watanabe T, et al: A20 targets caspase- 8 and FADD to protect HTLV-I-infected cells. Leukemia: Oct 6, 2015 (Epub ahead of print). http://dx.doi. org/10.1038/leu.2015.267.

25. Kang S, Fernandes-Alnemri T, Rogers C, Mayes L, Wang Y, Dillon C, Roback L, Kaiser W, Oberst A, Sagara J, et al: Caspase- 8 scaffolding function and MLKL regulate NLRP3 inflammasome activation downstream of TLR3. Nat Commun 6 : 7515,2015
26. Deng XU, Xia KE, Chen PO, Ali Sheikh MS, Yang DF, Li SM and Yang TL: Reversion of left ventricle remodeling in spontaneously hypertensive rats by valsartan is associated with the inhibition of caspase-3, -8 and -9 activities. Biomed Rep 3: 533-536, 2015.

27. Lin ML, Lu YC, Su HL, Lin HT, Lee CC, Kang SE, Lai TC, Chung JG and Chen SS: Destabilization of CARP mRNAs by aloe-emodin contributes to caspase-8-mediated p53-independent apoptosis of human carcinoma cells. J Cell Biochem 112: 1176-1191, 2011.

28. Kaseta MK, Gomatos IP, Khaldi L, Tzagarakis GP, Alevizos L, Themistocleous GS, Leandros E and Soucacos PN: Prognostic value of bax, cytochrome $\mathrm{C}$, and caspase- 8 protein expression in primary osteosarcoma. Hybridoma (Larchmt) 26: 355-362, 2007.

29. Kataoka T: The caspase- 8 modulator c-FLIP. Crit Rev Immunol 25: 31-58, 2005.

30. Zhao F, Huang W, Ousman T, Zhang B, Han Y, Clotaire DZ, Wang C, Chang H, Luo H, Ren X, et al: Triptolide induces growth inhibition and apoptosis of human laryngocarcinoma cells by enhancing p53 activities and suppressing E6-mediated p53 degradation. PLoS One 8: e80784, 2013.

31. Lee JY, Jung KH, Morgan MJ, Kang YR, Lee HS, Koo GB, Hong SS, Kwon SW and Kim YS: Sensitization of TRAIL-induced cell death by 20(S)-ginsenoside Rg3 via CHOP-mediated DR5 upregulation in human hepatocellular carcinoma cells. Mol Cancer Ther 12: 274-285, 2013

32. Kim EY, Yu JS, Yang M and Kim AK: Sub-toxic dose of apigenin sensitizes HepG2 cells to TRAIL through ERK-dependent up-regulation of TRAIL receptor DR5. Mol Cells 35: 32-40, 2013.

33. Carter BZ, Mak DH, Schober WD, Dietrich MF, Pinilla C, Vassilev LT, Reed JC and Andreeff M: Triptolide sensitizes AML cells to TRAIL-induced apoptosis via decrease of XIAP and p53-mediated increase of DR5. Blood 111: 3742-3750, 2008.

34. Gordy C, Liang J, Pua H and He YW: c-FLIP protects eosinophils from TNF- $\alpha$-mediated cell death in vivo. PLoS One 9: e107724, 2014.

35. Haag C, Stadel D, Zhou S, Bachem MG, Möller P, Debatin KM and Fulda S: Identification of c-FLIP(L) and c-FLIP(S) as critical regulators of death receptor-induced apoptosis in pancreatic cancer cells. Gut 60: 225-237, 2011.

36. Schleich K, Buchbinder JH, Pietkiewicz S, Kähne T, Warnken U, Öztürk S, Schnölzer M, Naumann M, Krammer PH and Lavrik IN: Molecular architecture of the DED chains at the DISC: regulation of procaspase- 8 activation by short DED proteins c-FLIP and procaspase-8 prodomain. Cell Death Differ: Oct 23, 2015 (Epub ahead of print). http://dx.doi.org/10.1038/cdd.2015.137.

37. Chen Z, Sangwan V, Banerjee S, Chugh R, Dudeja V, Vickers SM and Saluja AK: Triptolide sensitizes pancreatic cancer cells to TRAIL-induced activation of the death receptor pathway. Cancer Lett 348: 156-166, 2014

38. Jiang X, Chen Y, Fan X, Zhang H and Kun L: Osteogenesis and mineralization in a rabbit mandibular distraction osteogenesis model is promoted by the human LMP-1 gene. J Orthop Res 33: 521-526, 2015.

39. Ishioka S, Sagae S, Ito E and Kudo R: Ultrastructural study of benign, low-malignant potential (LMP), and malignant ovarian tumors. Med Electron Microsc 37: 37-44, 2004.

40. Pan H, Li X, Wang J, Zhang K, Yang H, Li Z, Zheng Z and Liu H: LIM mineralization protein-1 enhances bone morphogenetic protein-2-mediated osteogenesis through activation of ERK1/2 MAPK pathway and upregulation of Runx 2 transactivity. J Bone Miner Res 30: 1523-1535, 2015.

41. Aisa MC, Rahman S, Senin U, Maggio D and Russell RG: Cathepsin B activity in normal human osteoblast-like cells and human osteoblastic osteosarcoma cells (MG-63): Regulation by interleukin-1 beta and parathyroid hormone. Biochim Biophys Acta 1290: 29-36, 1996.

42. Jiao WJ, Xu J, Pan H, Wang TY and Shen Y: Effect of endothelin-1 in esophageal squamous cell carcinoma invasion and its correlation with cathepsin B. World J Gastroenterol 13: 4002-4005, 2007. 